\title{
Effects of Horse Riding Simulator on Pain, Oswestry Disability Index and Balance in Adults with Nonspecific Chronic Low Back Pain*
}

\author{
Shu-Yi Chen • Seung-Kyu Kim • Ki-Hyun Kim $\cdot$ In-Sil Lee ${ }^{2} \cdot$ Gak HwangBo $^{\dagger}$ \\ Department of Physical Therapy, Daegu University \\ ${ }^{1}$ Department of Physical Therapy, Kyungwoon University \\ ${ }^{2}$ Horse Industry Development Division
}

Received: August 24, 2016 / Revised: September 1, 2016 / Accepted: October 1, 2016

(c) 2016 J Korean Soc Phys Med

\section{| Abstract |}

PURPOSE: The purpose of this study was to investigate effects of Horse riding simulator exercise on pain, dysfunction and dynamic balance in adults with nonspecific chronic low back pain.

METHODS: In this study, total 19 college students usually complain of low back pain who were randomly divided into the horse riding simulator exercise group $(\mathrm{n}=10)$, lumbar strengthening exercise group $(\mathrm{n}=9)$ were recruited. Each group carried out for 30 minutes exercise three times a week for 4 weeks. Horse riding simulator exercise group carried out 15 minutes horse riding simulator exercise and 15 minutes lumbar strengthening exercise. Lumbar strengthening exercise group carried out 30 minutes lumbar strengthening exercise. Visual analogue scale (VAS) were measured for evaluation back pain. Korean oswestry disability index (KODI) were measured for dysfunction.

* This paper is abridgment of thesis for a master's degree of Shu-Yi Chen (2016).

†Corresponding Author : hbgak@daegu.ac.kr

This is an Open Access article distributed under the terms of the Creative Commons Attribution Non-Commercial License (http://creativecommons.org/licenses/by-nc/3.0) which permits unrestricted non-commercial use, distribution, and reproduction in any medium, provided the original work is properly cited.
Limits of stability (LOS) were measured for dynamic balance. RESULTS: VAS, KODI, LOS results showed a significant change within both horse riding simulator exercise group, lumbar strengthening exercise group.

CONCLUSION: Present study suggested that the horse riding simulator exercise can improve back pain, dysfunction, dynamic balance. Horse riding simulator exercise provides more convenience, interest and motivation than conversional therapy and it could be a possible approach to adults with nonspecific chronic low back pain.

Key Words: Horse riding simulator exercise, Low back pain, Dynamic balance

\section{Introduction}

Low back pain (LBP) is usually defined as pain, muscle tension, or stiffness localized below the costal margin and above the inferior gluteal folds, with or without leg pain (van Middelkoop et al., 2010). Many pain-affecting factors such as smoking, class, age, use of a computer, and lumbar support affect university students with nonspecific LBP (Taspinar et al., 2013).

Patients who have had LBP for more than three months 
have differences in static balance reactions in comparison to those without a medical history of LBP. They demonstrate increased sway and percent of limits to stability compared with pain-free subjects, which may indicate muscular imbalances (Cho et al., 2013).

There are many effective methods of treating chronic LBP, especially active approaches such as muscle strengthening exercises, core stabilization exercises, coordination exercises, general training, and aerobic exercise, which can reduce pain and improve functional abilities (Taylor et al., 2007; Son, 2015). Hippotherapy as a physical therapy treatment strategy is a program using rhythmical equine movement to achieve rehabilitation in patients with physical and mental disabilities. Since hippotherapy has been suggested as a form of physical therapy, recently, a horse-riding simulator was designed to provide realistic horse movement. The first study to assess the effect of hippotherapy simulator therapy on elderly patients with dementia showed a beneficial effect on balance improvement (Kim et al., 2008). The horse-riding simulator could also be useful for motor development and improvement in the static and dynamic balance of children with cerebral palsy (Lee et al., 2014). The horse-riding simulator was also used to relieve back pain and recover back function through developing trunk strength and balancing the ratio of extensor muscles to trunk flexor (Yoo et al., 2014).

Studies have shown beneficial effects of hippotherapy and the horse-riding simulator on patients with neurological disorders, especially children with cerebral palsy. However, there has not been sufficient study about treatment for musculoskeletal disorders, especially LBP. Therefore, in this study, we decided to perform horse-riding simulator exercises on adults with nonspecific chronic low back pain.

\section{Methods}

\section{Experimental subjects}

A total of 19 university students with nonspecific chronic low back pain, aged between 19 and 30, attending D University in Gyeongsan, South Korea, were included in this study. Prior to participation, all subjects read and signed the university-approved human subjects consent form. Selection criteria : Appeal to chronic back pain lasting longer than three months, Scores of visual analogue scale (VAS) are more than 3 points that affect the daily living, Scores of Korean Oswestry Disability Index (KODI) are more than 5 points that affect the daily living.

\section{Experimental design}

This study was divided into 2 groups: horse riding simulator with core strengthening exercise group and core strengthening exercise group. After the pre-test, apply the intervention about three times a week for 4 consecutive weeks before a post-test.

The horse riding simulator used in this study was an indoor riding machine (Hongin Leports, South Korea), simulating riding a real horse through the visual information that appeared on the front screen by diving the virtual environment. Horse riding simulator exercise conducted three times a week for four consecutive weeks, 15 minutes per time. Then the core strengthening exercise was performed for 15 minutes.

To compare the effects, core muscle strengthening exercise was undertaken in the control group, which was a modified exercise program based on the core strengthening exercise (Akuthota and Nadler, 2004). Intervention was applied over four weeks, three times per week with each session lasting 30 minutes. The exercise program consisted of six movements for one set. Each movement was hold for 5 seconds with 8 repetitions. All the programs were repeated for 5 times for one set. 


\section{Experimental measurements}

The reliable visual analogue scale (VAS) was applied to evaluate the pain intensity of subjects (Revill et al., 1976). The Oswestry Low Back Pain Disability Questionnaire was developed to measure the relief and aggravation of the symptoms in low back pain patients (Fairbank et al., 1980). The Oswestry Low Back Pain Disability Questionnaire used in this study has been translated to Korean Version and its reliability and validity have been tested and approved (Jeon et al., 2006).

In order to measure the balance ability of the subjects, we used Biorescue (RM Ingenierie, France) equipment which can test the Limits of stability (LOS). LOS is one of the dynamic balance test and it measure 4 directions (left, right, forward, backward) stable movement range of center of gravity (COG).

\section{Statistical analysis}

Data were expressed as means \pm standard deviations. To analyze the distribution of the data, the Shapiro-Wilk test was used. Independent t-test was used to analyze the data in order to compare differences of the general characteristics of the subjects among the groups. Paired T-test was used to analyze the data in order to compare differences within the group before and after the interventions for low back pain. Independent $t$-test was used to evaluate the statistical significance of differences among the two groups. Statistical analysis was conducted using SPSS for Windows (ver 20.0) and the statistical significance level was set to $\mathrm{p}<.05$.

\section{Results}

Comparison within group revealed that the Exercise group and Control group showed significant differences after the intervention in VAS, KODI, and LOS ( $<<.05)$. Comparison between the groups revealed no significant difference between the groups in VAS, KODI, and LOS before and after the intervention ( $\mathrm{p}>$.05) (Table 1).

\section{Discussion}

Based on systematic reviews of the global prevalence of LBP, it is clear that it continues to be a common problem globally.

In the results of pain intensity in this study, VAS scores showed a significant decrease after both interventions. These findings are comparable to those obtained by Yoo et al. (2014), which found that eight weeks of a horse simulator riding program significantly reduced back pain and improved trunk flexor and extensor muscle strength in young men with chronic LBP.

Consistent with the results of pain intensity in this study, the KODI scores as a result of functional disability significantly decreased after all interventions. In parallel to the findings of this study, Byeon (2014) found a significant decrease in the disability index in patients with LBP after an eight-week horse-riding simulator exercise. The strengthening exercise was also effective in reducing pain and improving disability and the physical component of quality of life in patients with chronic LBP (Gatti et al., 2011). From the results above, a horse-riding simulator is considered to be effective in relieving low back pain and improving disability.

A few studies have shown that patients with chronic LBP showed altered automatic postural coordination, a different trunk motor, increased difficulty in adapting to changing conditions, and a greater postural sway under certain conditions in upright standing compared to those without LBP (Henry et al., 2006; Mann et al., 2010; Mientjes and Frank, 1999; Willigenburg et al., 2013). According to the results of dynamic balance ability in this study, the stable balance ranges (forward, back, left, and right) were significantly increased after all interventions. 
Table 1. Comparison of back pain and balance for each group

$($ Mean $\pm S D)$

\begin{tabular}{|c|c|c|c|c|c|c|c|}
\hline \multicolumn{2}{|c|}{ Variable } & Group & Pre & Post & Post-pre & $\mathrm{t}$ & $\mathrm{p}$ \\
\hline \multirow[b]{4}{*}{ Back } & \multirow{4}{*}{$\begin{array}{l}\text { VAS } \\
\text { (score) }\end{array}$} & Exercise & $49.10 \pm 18.89$ & $22.70 \pm 17.25$ & $-26.40 \pm 13.09$ & 6.37 & $.000^{*}$ \\
\hline & & Control & $43.66 \pm 8.23$ & $22.55 \pm 7.77$ & $-21.11 \pm 3.33$ & 19.00 & $.000^{*}$ \\
\hline & & $\mathrm{t}$ & & & -1.175 & & \\
\hline & & $\mathrm{p}$ & & & .256 & & \\
\hline \multirow{4}{*}{ pain } & \multirow{4}{*}{$\begin{array}{l}\text { KODI } \\
\text { (score) }\end{array}$} & Exercise & $9.60 \pm 3.53$ & $4.90 \pm 4.88$ & $-4.70 \pm 2.26$ & 6.56 & $.000^{*}$ \\
\hline & & Control & $10.55 \pm 4.06$ & $5.00 \pm 2.29$ & $-5.56 \pm 2.55$ & 6.52 & $.000^{*}$ \\
\hline & & $\mathrm{t}$ & & & .769 & & \\
\hline & & $\mathrm{p}$ & & & .453 & & \\
\hline \multirow{16}{*}{ Balance } & \multirow{4}{*}{$\begin{array}{c}\text { Left } \\
\left(\mathrm{mm}^{2}\right)\end{array}$} & Exercise & $3971.40 \pm 1.69$ & $5725.50 \pm 1.73$ & $1754.10 \pm 1111.50$ & -4.99 & $.001 *$ \\
\hline & & Control & $3714.55 \pm 1.42$ & $5447.44 \pm 1.38$ & $1732.89 \pm 1449.79$ & -3.58 & $.007 *$ \\
\hline & & $\mathrm{t}$ & & & .035 & & \\
\hline & & $\mathrm{p}$ & & & .972 & & \\
\hline & \multirow{4}{*}{$\begin{array}{l}\text { Right } \\
\left(\mathrm{mm}^{2}\right)\end{array}$} & Exercise & $3761.00 \pm 2.37$ & $6140.40 \pm 2.94$ & $2379.40 \pm 3109.60$ & -2.42 & $.039 *$ \\
\hline & & Control & $3715.33 \pm 1.63$ & $5950.00 \pm 977.48$ & $2234.67 \pm 1931.22$ & -3.47 & $.008 *$ \\
\hline & & $\mathrm{t}$ & & & .123 & & \\
\hline & & $\mathrm{p}$ & & & .904 & & \\
\hline & \multirow{4}{*}{$\begin{array}{c}\text { Forward } \\
\left(\mathrm{mm}^{2}\right)\end{array}$} & Exercise & $4808.90 \pm 2.73$ & $7602.10 \pm 3.19$ & $2793.20 \pm 3476.85$ & -2.54 & $.032 *$ \\
\hline & & Control & $7602.10 \pm 3.19$ & $7251.44 \pm 2.12$ & $2554.00 \pm 2457.19$ & -3.11 & $.014 *$ \\
\hline & & $\mathrm{t}$ & & & .174 & & \\
\hline & & $\mathrm{p}$ & & & .864 & & \\
\hline & \multirow{4}{*}{$\begin{array}{c}\text { Backward } \\
\left(\mathrm{mm}^{2}\right)\end{array}$} & Exercise & $2623.60 \pm 1.54$ & $4268.60 \pm 1.24$ & $1645.00 \pm 1603.67$ & -3.24 & $.010^{*}$ \\
\hline & & Control & $2399.22 \pm 1.10$ & $3771.33 \pm 2.12$ & $1372.11 \pm 1701.36$ & -2.41 & $.042 *$ \\
\hline & & $\mathrm{t}$ & & & .359 & & \\
\hline & & $\mathrm{p}$ & & & .724 & & \\
\hline
\end{tabular}

${ }^{*} \mathrm{p}<.05$

VAS: visual analogue scale, KODI: Korean oswestry disability index, LOS: Limited of stability

To date, studies about hippotherapy improving balance have been focused mainly on children with cerebral palsy. But recent studies focusing on adults, such as our study, reported that an eight-week hippotherapy program improved balance and gait function in patients with chronic brain disorders and in the elderly (de Araujo et al., 2013; Sunwoo et al., 2012). Carpes et al. (2008) also found that the body balance as well as the range of walking motion in females were improved after trunk strength and stability training. The study reveal that both horse riding simulator exercise and lumbar strentening have a positive impact on the patients who has low back pain that is, it has same effect both groups. According to all the results of this study, both lumbar strentening and the horse-riding simulator are recommended as effective treatments to relieve pain and to improve functional disability and balance for nonspecific chronic low back pain.

\section{Conclusion}

This study was performed to investigate the effects of 
a horse-riding simulator on pain relief, dysfunction, and balance in adults with nonspecific chronic low back pain.

It is difficult to generalize for the various patients who complained of different back. This pain results in hindrances in daily life due to the subjective pains of the patients. However, a horse-riding simulator can be presented as one of the available methods to help relieve back pain, according to our results. A horse-riding simulator in parallel with existing back muscle strengthening exercises can increase the convenience, interest, and motivation to use these exercises. Therefore, using a horse-riding simulator can be recommended as a new treatment method to present support for low back pain.

Further investigation should be considered regarding the effects of the horse-riding simulator on posture muscles to maintain the body as well as studies of its effectiveness for back pain in accordance with specific programs or strengths.

\section{References}

Akuthota V, Nadler SF. Core strengthening. Arch Phys Med Rehabil. 2004;85(3-1):S86-92.

Byeon, SJ. Effects of Horse-riding Simulator Exercise on Oswestry Disability Index, Balance, and Muscle Activity in Twentysomethings with Low Back Pain. Daegu University. Mster's Degree. 2014.

Carpes FP, Reinehr FB, Mota CB. Effects of a program for trunk strength and stability on pain, low back and pelvis kinematics, and body balance: a pilot study.

J Bodyw Mov Ther. 2008;12(1):22-30.

Cho SH, Kim JH, Choi MH. The effect of short-term lumbar stabilization exercise for lumbar muscle strength and postural balance on chronic LBP. J Korean Soc Phys Med. 2013;8(3):295-302.

de Araujo TB, de Oliveira RJ, Martins WR, et al. Effects of hippotherapy on mobility, strength and balance in elderly. Arch Gerontol Geriatr. 2013;56(3): 478-81.

Fairbank JC, Couper J, Davies JB, et al. The Oswestry low back pain disability questionnaire. Physiotherapy. 1980;66(8):271-73.

Gatti R, Faccendini S, Tettamanti A, et al. Efficacy of trunk balance exercises for individuals with chronic low back pain: a randomized clinical trial. J Orthop Sports Phys Ther. 2011;41(8):542-52.

Henry SM, Hitt JR, Jones SL, et al. Decreased limits of stability in response to postural perturbations in subjects with low back pain. Clin Biomech (Bristol, Avon). 2006;21(9):881-92.

Jeon CH, Kim DJ, Kim SK, et al. Validation in the cross-cultural adaptation of the Korean version of the Oswestry Disability Index. J Korean Med Sci. 2006;21(6): 1092-7.

Kim DH, Kim SJ, Bae SS, et al. The effect of indoor horseback-riding machine on the balance of the elderly with dementia. J Korean Soc Phys Med. 2008;3(4):235-46

Lee CW, Kim SG, Na SS. The effects of hippotherapy and a horse riding simulator on the balance of children with cerebral palsy. J Phys Ther Sci. 2014;26(3):423-5.

Mann L, Kleinpaul JF, Pereira Moro AR, et al. Effect of low back pain on postural stability in younger women: influence of visual deprivation. J Bodyw Mov Ther. 2010;14(4):361-6.

Mientjes MI, Frank JS. Balance in chronic low back pain patients compared to healthy people under various conditions in upright standing. Clin Biomech (Bristol, Avon). 1999;14(10):710-6.

Revill SI, Robinson JO, Rosen M, et al. The reliability of a linear analogue for evaluating pain. Anaesthesia. 1976;31(9):1191-8.

Son $\mathrm{HH}$. The effects of stabilization exercise with abdominal breath on balance and oswestry disability index for low back pain patients. J Korean Soc Phys Med. 2015;10(1):107-13 
Sunwoo H, Chang WH, Kwon JY, et al. Hippotherapy in adult patients with chronic brain disorders: a pilot study. Ann Rehabil Med. 2012;36(6):756-61.

Taspinar F, Taspinar B, Cavlak U, et al. Determining the pain-affecting factors of university students with nonspecific low back pain. J Phys Ther Sci. 2013;25(12):1561-4.

Taylor NF, Dodd KJ, Shields N, et al. Therapeutic exercise in physiotherapy practice is beneficial: a summary of systematic reviews 2002-2005. Aust J Physiother. 2007;53(1):7-16. van Middelkoop M, Rubinstein SM, Verhagen AP, et al. Exercise therapy for chronic nonspecific low-back pain. Best Pract Res Clin Rheumatol. 2010;24(2):193-204.

Willigenburg NW, Kingma I, van Dieen JH. Center of pressure trajectories, trunk kinematics and trunk muscle activation during unstable sitting in low back pain patients. Gait Posture. 2013;38(4):625-30.

Yoo JH, Kim SE, Lee MG, et al. The effect of horse simulator riding on visual analogue scale, body composition and trunk strength in the patients with chronic low back pain. Int J Clin Pract. 2014;68(8):941-9. 